\title{
Products deriving from microbial fermentation are linked to insulinaemic response in pigs fed breads prepared from whole-wheat grain and wheat and rye ingredients
}

\author{
Peter Kappel Theil ${ }^{1 *}$, Henry Jørgensen ${ }^{1}$, Anja Serena ${ }^{1}$, Jessica Hendrickson ${ }^{2}$ and \\ Knud Erik Bach Knudsen ${ }^{1}$ \\ ${ }^{1}$ Department of Animal Health and Bioscience, Faculty of Agricultural Sciences, University of Aarbus, Blichers Allé 20, \\ DK-8830 Tjele, Denmark \\ ${ }^{2}$ Department of Animal Science, University of Illinois, Urbana, IL 61801, USA
}

(Received 28 January 2010 - Revised 10 August 2010 - Accepted 25 August 2010 - First published online 6 October 2010)

\section{Abstract}

The effects of wheat and rye breads made from whole-wheat grain (WWG), wheat aleurone flour (WAF) or rye aleurone flour (RAF) on net portal absorption of carbohydrate-derived nutrients (glucose, SCFA and lactate) and apparent insulin secretion were studied in a model experiment with catheterised pigs. The breads were similar in dietary fibre (DF, $120-125 \mathrm{~g} / \mathrm{kg}$ DM) but differed in arabinoxylans $(50-62 \mathrm{~g} / \mathrm{kg}), \beta$-glucans $(4-9 \mathrm{~g} / \mathrm{kg})$ and content of soluble DF $(13-29 \mathrm{~g} / \mathrm{kg})$. Six pigs in a repeated $3 \times 3$ crossover design were fitted with catheters in the portal vein and the mesenteric artery and a portal flow probe. Pigs were fed three meals daily (at $09.00,14.00$ and 19.00 hours), and blood profiles were collected repeatedly from 08.30 until 19.00 hours once weekly. Net portal absorption of glucose was similar among breads and between meals. In contrast, insulin secretion was lowest $(P<0.05)$ in pigs fed RAF bread $(3.9 \mathrm{nmol} / \mathrm{h})$, intermediate in pigs fed WAF bread $(5.4 \mathrm{nmol} / \mathrm{h})$ and highest in pigs fed WWG bread $(5.9 \mathrm{nmol} / \mathrm{h})$, indicating that RAF bread improved insulin economy. Portal concentrations of propionate, butyrate and valerate were high, intermediate and low $(P<0 \cdot 05)$ when pigs were fed RAF, WAF and WWG breads, respectively. Insulin secretion was higher $(P<0 \cdot 001)$, and portal absorption of SCFA was lower $(P<0.05)$ after the first daily meal than after the second daily meal $(8.8 v .4 .4 \mathrm{nmol} / \mathrm{h})$. A low insulin response was associated with high portal absorption of SCFA. In conclusion, RAF bread was able to improve insulin economy compared to WWG bread.

Key words: Dietary fibre: Insulin response: Quantitative absorption: Pigs: SCFA

Cereal foods are an important contributor of carbohydrates and dietary fibre (DF) particularly in Northern Europe. In Denmark, bread accounts for approximately $17 \%$ of dietary energy intake ${ }^{(1)}$ and, along with other cereal products, for approximately $60 \%$ of the intake of $\mathrm{DF}^{(2)}$. The consumption pattern of bread in Denmark, however, has been changing during the last two decades, as the white type of bread based on refined wheat starch has replaced whole-grain cereal bread, particularly whole-grain rye bread $^{(1)}$. This is a most regrettable development as whole-grain cereals are superior to refined starch in terms of DF, phytochemicals, vitamins and minerals ${ }^{(3)}$. Epidemiological studies have pointed to whole-grain cereal products as factors that may protect against CVD, some forms of cancer and type 2 diabetes $^{(3,4)}$.
Development of new ingredients high in DF and other nutrients is therefore most welcome.

An epidemiological study of Salmerón et al. ${ }^{(5)}$ using prospective data from more than 65000 women in the Nurses' Health Study pointed to the intake of cereal DF and the glycaemic load as factors that reduce the risk of type 2 diabetes. A meta-analysis based on data from forty-five relevant publications reached the same conclusion ${ }^{(6,7)}$. Lower-glycaemic index (GI) diets reduced both fasting blood glucose and glycated protein independently of variance in available carbohydrates and DF intake ${ }^{(6)}$. In addition, high DF intake further improved both blood glucose and glycated protein control. It was also found that insulin sensitivity was improved by lower GI, by higher DF intake in persons with type 2 diabetes, in overweight

Abbreviations: AX, arabinoxylans; DF, dietary fibre; GI, glycaemic index; RAF, rye aleurone flour; WAF, wheat aleurone flour; WFL, wheat flour; WWG, whole-wheat grain.

*Corresponding author: Dr P. K. Theil, fax +458999 13 78, email peter.theil@agrsci.dk 
and obese persons, and in all studies combined ${ }^{(6)}$. A lower GI with cereal-based foods is usually related to soluble DF, $\beta$-glucan and arabinoxylans (AX), as these polysaccharides may interfere with the digestion and absorption processes either by delaying gastric emptying or by slowing the uptake of nutrients from the small intestine ${ }^{(8)}$. However, the efficiency of these polymers in the short-term regulation of GI varies depending on whether they are provided as isolates or naturally present in the food ${ }^{(9-11)}$. More recent studies have emphasised the importance of insoluble non-viscous DF for improving insulin sensitivity and glucose homoeostasis ${ }^{(12,13)}$. Since insoluble DF has little or no influence on digestive events in the small intestine, the beneficial effects on insulin sensitivity and glucose homoeostasis must involve colonic metabolism ${ }^{(12,13)}$. The metabolism of DF in the large intestine leads to the production of SCFA through colonic fermentation, and the main products are acetate, propionate and butyrate ${ }^{(14)}$. These SCFA are rapidly absorbed from the gut lumen, a fraction is metabolised by the colonic epithelium, but a significant part enters the portal and peripheral circulation $^{(14,15)}$. Enhanced SCFA production, and butyrate in particular, has been linked to improved insulin sensitivity and glucose homoeostasis ${ }^{(12,13,16-18)}$. The mechanism(s) are not entirely clear, but appear to involve adipose tissue metabolism ${ }^{(16,17)}$. So, the effects of whole-grain cereals on glucose homoeostasis are dual - soluble DF interferes with digestion and absorption events in the small intestine, while the insoluble DF executes its action through fermentation in the large intestine.

Low-GI foods have also been linked to improved postprandial glucose regulation even after the consumption of a consecutive 'second meal' that was standardised, i.e. without dietary manipulation ${ }^{(19,20)}$. Improved glucose homoeostasis was seen from breakfast to lunch or from a late evening meal to breakfast in human studies ${ }^{(20)}$. Inclusion of DF from barley, in particular, has shown promising effects ${ }^{(13,20)}$. However, in spite of decreased postprandial plasma glucose, the secondary meal effect did not affect the plasma content of insulin, but was positively correlated with fasting levels of NEFA in plasma, suggesting that types and proportion of assimilated products (glucose, lactate and SCFA) deriving from carbohydrate interact with glucose homoeostasis ${ }^{(13,20)}$.

A recent study with twenty ileal cannulated pigs fed the same breads as in the present study showed that the ileal starch digestibility was lower for the rye bread than the two wheat breads, and the variation in ileal viscosity across breads was related to the concentration and molecular weight of $\mathrm{AX}$ across diets ${ }^{(21,22)}$. It was also found that the flow rate of digesta through the small intestine was higher after the first daily meal than after the second daily meal, due to less gut fill following a long (14h) fasting period overnight. The more rapid flow, however, had only a minor impact on the overall ileal digestibility of nutrients ${ }^{(21)}$. We therefore hypothesised that dietary inclusion of DF from rye, which increases luminal viscosity and reduces starch digestibility, would decrease the glycaemic load and insulinaemic response. Furthermore, the experiment aimed at testing which role the fasting period before a meal plays on insulinaemic and glycaemic responses, because the fasting period before the first and second daily meals in human subjects differs greatly.

\section{Materials and methods}

\section{Breads}

The breads were made of standard white wheat flour (WFL), whole-wheat grain (WWG), wheat aleurone-rich flour (WAF) and rye aleurone-rich flour (RAF). The WFL and WWG breads were produced at Holstebro Technical College (Holstebro, Denmark), and the WAF and RAF breads were baked in a local bakery (Konditor-Bager Ørum, Denmark). The ingredients for the WFL bread were white wheat flour (Triticum aestivum $\mathrm{L}$. cv. Tiger), purified wheat fibres (Vitacel R200; J. Rettenmaier and Söhne GmbH, Rosenberg, Germany), rapeseed oil, sugar, salt, wheat gluten (LCH A/S, Frederiksberg, Denmark) and yeast, while in WWG, WAF and RAF breads, whole-grain wheat (BFEL Karlsruhe, Germany), wheat aleurone-rich flour (Bühler AG, Uzwil, Switzerland) and rye aleurone-rich flour (Raisio plc, Raisio, Finland) replaced the white wheat flour and purified wheat fibre on an iso-DF basis. After production, the breads were cut into pieces and mixed. After weighing, meal portions were frozen at $-20^{\circ} \mathrm{C}$ and thawed immediately before consumption. The four breads were balanced with regard to starch, protein, fat, energy and DF, but they varied in DF characteristics (see Tables 1 and 2 for dietary ingredients and composition).

Surgery, post-surgery care, housing and rearing were in compliance with Danish laws and regulations for the humane care and use of animals in research (The Danish Ministry of Justice, Animal Testing Act (Consolidation Act no. 726 of 9 September 1993 as amended by Act no. 1081 of 20 December 1995)). Furthermore, the Danish Animal Experimentation Inspectorate approved the study protocols and supervised the experiment. The health of the animals was monitored, and no serious illness was observed.

Daily feed allowance was 2.7 times of maintenance $\left(2.7 \times 460.2 \mathrm{~kJ}(110 \mathrm{kcal})\right.$ of $\mathrm{DE} / \mathrm{kg}^{0.75}$; NRC, 1998), which supplied $210 \mathrm{~g} \mathrm{DF} / \mathrm{d}$. The daily ration was divided into three meals, and 40, 40 and $20 \%$ of daily allowance was given at first (09.00 hours), second (14.00 hours) and third meals ( 19.00 hours) to mimic the diurnal variation in human intake of DF.

\section{Animals}

The pigs used in the study were from the swineherd at Aarhus University, Faculty of Agricultural Sciences, 
Table 1. Ingredients list of experimental diets

\begin{tabular}{|c|c|c|c|c|}
\hline & \multicolumn{3}{|c|}{ Experimental diets } & \multirow{2}{*}{$\begin{array}{c}\text { Washou } \\
\text { diet } \\
\text { WFL }\end{array}$} \\
\hline & WWG & WAF & RAF & \\
\hline \multicolumn{5}{|l|}{ Ingredients ( $\mathrm{g} / \mathrm{kg}$, as-fed basis) } \\
\hline Whole-wheat grain & 813 & & & \\
\hline Standard wheat flour & & & & 711 \\
\hline Rye flour (3-3.5\% ash)* & & & 365 & \\
\hline Wheat aleuronet & & 214 & & \\
\hline Wheat starch $\ddagger$ & & 516 & 359 & \\
\hline Wheat gluten $\ddagger$ & 36 & 116 & 116 & 59 \\
\hline $\begin{array}{l}\text { Vitacel R200 (99.5\% } \\
\text { cellulose)§ }\end{array}$ & & & & 69 \\
\hline Rapeseed oil & 76 & 79 & 85 & 86 \\
\hline Sugar & 15 & 15 & 15 & 15 \\
\hline Baker's yeast & 15 & 15 & 15 & 15 \\
\hline Vitamin-mineral mixture & 4 & 4 & 4 & 4 \\
\hline \multicolumn{5}{|c|}{ 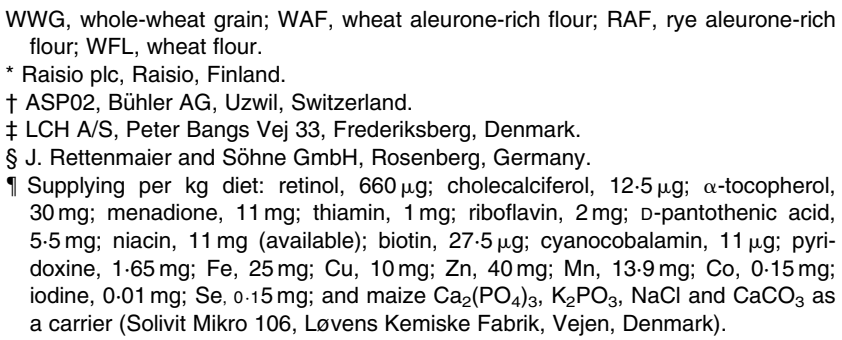 } \\
\hline
\end{tabular}

Foulum, Denmark. Six female LY pigs $(56.5$ (SEM 1.8) kg) were included in the experiment, which was designed as a repeated $3 \times 3$ Latin square design. The pigs were adapted to the pen for $5 \mathrm{~d}$, and then the animals were surgically fitted with a flow probe (Transonic, 20A probe, $20 \mathrm{~mm}$; Transonic System, Inc., Ithaca, NY, USA) around

Table 2. Chemical composition of the experimental diets

\begin{tabular}{|c|c|c|c|c|}
\hline & \multicolumn{3}{|c|}{ Experimental diets } & \multirow{2}{*}{$\begin{array}{c}\text { Washou } \\
\text { diet } \\
\text { WFL }\end{array}$} \\
\hline & WWG & WAF & RAF & \\
\hline \multicolumn{5}{|c|}{ Chemical composition (g/kg DM) } \\
\hline DM (g/kg as-fed basis) & 654 & 704 & 691 & 639 \\
\hline Protein $(\mathrm{N} \times 6 \cdot 25)$ & 173 & 177 & 173 & 168 \\
\hline Fat & 137 & 134 & 146 & 128 \\
\hline Ash & 43 & 58 & 41 & 37 \\
\hline Carbohydrates & 630 & 589 & 626 & 641 \\
\hline Sugars & 19 & 14 & 17 & 11 \\
\hline Fructose & 12 & 10 & 10 & 8 \\
\hline Glucose & 5 & 3 & 4 & 2 \\
\hline Sucrose & 2 & 1 & 3 & 1 \\
\hline Starch & 506 & 470 & 505 & 513 \\
\hline Total NSP & 105 & 105 & 104 & 117 \\
\hline Fructans & 3 & 2 & 10 & 2 \\
\hline$A X$ & 61 & 62 & 50 & 26 \\
\hline$\beta$-Glucan & 4 & 8 & 9 & 1 \\
\hline Cellulose & 17 & 14 & 12 & 66 \\
\hline Soluble NSP & 26 & 15 & 39 & 16 \\
\hline Fructans & 3 & 2 & 10 & 2 \\
\hline $\mathrm{AX}$ & 17 & 9 & 19 & 11 \\
\hline$\beta$-Glucan & 1 & 0 & 2 & 0 \\
\hline Klason lignin & 22 & 23 & 26 & 10 \\
\hline Total dietary fibre & 124 & 125 & 120 & 125 \\
\hline $\begin{array}{c}\text { Gross energy } \\
\text { (MJ/kg DM) }\end{array}$ & $20 \cdot 35$ & $20 \cdot 35$ & $20 \cdot 43$ & 20.56 \\
\hline Viscosity $(m P \times s)$ & 1.42 & 0.95 & $2 \cdot 20$ & $1 \cdot 30$ \\
\hline
\end{tabular}

WWG, whole-wheat grain; WAF, wheat aleurone-rich flour; RAF, rye aleurone-rich flour; WFL, wheat flour; $A X$, arabinoxylans. the portal vein, a catheter in the portal vein and a catheter in the mesenteric artery. The surgical procedures have been described by Jørgensen et al. ${ }^{(23)}$. After the surgery, the animals were allowed a $5-7 \mathrm{~d}$ recovery period before entering a $21 \mathrm{~d}$ experimental period (three consecutive experimental weeks). In each experimental week, the pigs were fed a washout diet (WFL) on days 1-3, and then the pigs were fed one of the three experimental breads on days $4-7$. On day 7 , fasting blood samples ( -30 min before the first daily meal) were collected from the portal vein and the mesenteric artery, and then consecutive blood samples were drawn from the portal vein and the mesenteric artery at 0, 15, 30, 45, 60, 90, 120, 180, 240, $300 \mathrm{~min}$ (second daily meal), 315, 330, 345, 360, 390, 420, 480, 540 and $600 \mathrm{~min}$ relative to feeding the first daily meal. Blood samples were collected in $\mathrm{Na}$ heparin vacutainers, and plasma was harvested; $9+4 \mathrm{ml}$ of blood was collected at $-30 \mathrm{~min}$ (fasting), $9 \mathrm{ml}$ of blood was collected at 15, 60, 120, 180, 240, 300, 315, 360, 420, 480, 540 and $600 \mathrm{~min}$, whereas $2 \mathrm{ml}$ of blood was collected at the remaining sampling times. Blood was replaced with saline. Four artery (Ia, IIa, IIIa and IVa) and four venous (Iv, IIv, IIIv and IVv) plasma samples were pooled from $9 \mathrm{ml}$ blood samples to represent mean content of SCFA in blood in the periods 0-150, 150-300, 300-450 and 450-600 min after the morning feeding, respectively. Packed cell volume was monitored once per $\mathrm{h}$ and was always higher than $26 \%$. Blood flow in the portal vein was recorded immediately before blood collection as a mean of sixty recordings within a minute. Once a week, the pigs were weighed and received $400 \mathrm{mg}$ of $\mathrm{Fe}$ supplement injected intramuscularly (Uniferon ${ }^{\circledR}$; Pharmacosmos A/S, Holbæk, Denmark).

The pigs were kept individually in pens $(2 \times 2 \mathrm{~m})$, and an elevated grid made of plastic covering half of the pen allowed the pigs to rest and stay dry. The pigs had access to water ad libitum, whereas no straw was supplied. The pigs were allowed $45 \mathrm{~min}$ to complete ingestion of a meal, whereupon the feed was removed forcing the pigs to eat up as fast as possible. Feed residues were collected and weighed, and DM content was analysed to allow correction of feed intake. Feed intake at a given meal was recorded to evaluate intake of starch, whereas intake during the last three meals was summed to evaluate the intake of DF.

\section{Analytical methods}

All chemical analyses of breads were performed in duplicate on freeze-dried materials. The DM was measured by drying to constant weight (mostly $20 \mathrm{~h}$ ) at $103^{\circ} \mathrm{C}$, and ash was analysed according to the AOAC method ${ }^{(24)}$. Nitrogen was measured by DUMAS ${ }^{(25)}$, and protein was calculated as $\mathrm{N} \times 6 \cdot 25$. Gross energy was determined with a LECO AC 300 automated calorimeter system 789-500 (LECO, St Joseph, MI, USA) (ISO 9831:1998). Fat was extracted 
with a monophasic mixture of chloroform, methanol and water as described by Bligh \& Dyer ${ }^{(26)}$ after hydrochloric acid hydrolysis.

Dietary contents of sugars (glucose, fructose and sucrose) and fructans were analysed as described by Larsson \& Bengtsson $^{(27)}$, and starch and NSP were analysed as described by Bach Knudsen ${ }^{(28)}$. Klason lignin was measured as the sulphuric acid-insoluble residue as described by Theander \& Áman ${ }^{(29)}$. Pooled plasma samples were analysed for SCFA essentially as described by Brighenti ${ }^{(30)}$, using 2-ethyl butyrate (Fluka no. 03 190; Sigma Aldrich, St Louis, MO, USA) as an internal standard, rather than isovaleric acid, because 2-ethyl butyrate is not produced by the microflora. All collected plasma samples were analysed for insulin by time-resolved fluoroimmunoassay as described by Løvendahl \& Purup ${ }^{(31)}$ and for lactate and glucose according to standard procedures such as lactatoxidase, glucose hexokinase II and enzymatic colorimetric determination, respectively (Siemens Diagnostics ${ }^{\circledR}$ Clinical Methods for ADVIA 1650, Tarrytown, NY, USA). NEFA were determined using the Wako, NEFA C ACS-ACOD assay method (Wako Chemicals GmbH, Neuss, Germany). Lactate, glucose and NEFA analyses were performed on an ADVIA 1650 autoanalyzer (Siemens Healthcare Diagnostics).

\section{Calculations}

The net absorption of glucose, lactate and SCFA into the portal vein and apparent production of insulin were calculated from the porto-arterial differences and the portal flow measurements according to Rérat et al. ${ }^{(32)}$ using the following equation:

$$
\begin{gathered}
q=\left(C_{\mathrm{p}}-C_{\mathrm{a}}\right) \cdot F(\mathrm{~d} t), \\
\underset{t_{0}}{\stackrel{t_{n}}{Q}}=\sum q,
\end{gathered}
$$

where $q$ is the amount of glucose, lactate, SCFA absorbed or insulin produced within the time period $\mathrm{d} t ; C_{\mathrm{p}}$ is the concentration in the portal vein; $C_{\mathrm{a}}$ is the concentration in the mesenteric artery; $F$ is blood flow in the portal vein; and $Q$ is the amount absorbed from $t_{0}$ to $t_{n}$ or insulin produced from $t_{0}$ to $t_{n}$. The calculated insulin production can only be described in the present study as apparent because insulin has a pulsatile secretion, it is broken down by the liver and kidney and it has a variable halflife value $(10-30 \mathrm{~min})$.

The energy coefficients reported for glucose, lactate and specific SCFA ${ }^{(33)}$ were used when calculating portal absorption of energy derived from glucose, lactate and SCFA.

\section{Statistics}

Effects of breads, meal, time and their two-factor interactions were analysed as repeated measurements using the MIXED procedure of Statistical Analysis Software (SAS Institute Inc., Cary, NC, USA) as described by Littell et $a l .{ }^{(34)}$. Level of significance was detected at $P \leq 0.05$, while a tendency was reported when $P \leq 0 \cdot 10$.

Plasma variables were analysed using the following normal mixed model:

$$
\begin{aligned}
Y_{(i j k l m n)}= & \mu+\alpha_{i}+\beta_{j}+\gamma_{k}+\alpha \beta_{i j}+\alpha \gamma_{i k}+\beta \gamma_{j k}+\delta_{l}+\rho_{m} \\
& +v_{i l m}+\tau_{i l m n}+e_{i j k l m n}
\end{aligned}
$$

where $Y_{i j k l m n}$ is the dependent variable; $\alpha_{i}$ is the bread ( $i=\mathrm{WWG}$, WAF or RAF); $\beta_{j}$ is the effect of meal $(j=1$ or 2 ), which was also associated with length of time without feed before the meal (14 and $5 \mathrm{~h}$, respectively); note that the postprandial phase following the third meal within a day was not studied; $\gamma_{k}$ is the time after a meal ( $k=15,30,45,60,90,120,180,240$ and $300 \mathrm{~min}$ ); $\alpha \beta_{i j}$, $\alpha \gamma_{i k}$ and $\beta \gamma_{j k}$ are two-factor interaction terms; and $\delta_{l}$ is the week $(l=1,2$ or 3$)$. The three terms $\rho_{m}(m=$ pig $1, \ldots, 6), v_{i l m}$ and $\tau_{\text {ilmn }}$ ( $n=$ meal 1 and 2) accounted for repeated measurements being performed on the same pig $\left(\boldsymbol{\rho}_{m}\right)$, on the same pig within period $\left(\boldsymbol{v}_{i l m}\right)$ and on the same pigs within period and meal $\left(\tau_{i l m n}\right)$, respectively, whereas $e_{i j k l m n}$ describes the random error. The covariance structure of $\tau_{i l m n}$ was modelled using the spatial power option, which takes into account the different intervals between repeated measurements. Data on insulin concentrations in the mesenteric artery and the portal vein and apparent insulin production were transformed to $\ln (x)$ before performing the statistical analysis to obtain variance homogeneity. Plasma levels of SCFA (part of Table 4) and portal absorption of energy derived from glucose, lactate and SCFA (Table 5) were based on the pooled plasma samples. Thus, the above-mentioned model was applied, with the exception that $\gamma_{k}$ describes the two absorptive phases after a meal $(k=1,2$ refer to $0-2.5$ and $2.5-5 \mathrm{~h}$ post feeding, respectively), and a simple covariance structure of $\tau_{\text {ilmn }}$ was assumed. If $P>0.05$ was found for bread $\times$ meal, meal $\times$ phase or bread $\times$ phase, the nonsignificant interaction terms were removed and the statistical model was reanalysed.

\section{Results}

\section{Diets and dietary intake of nutrients}

The diets were formulated to provide equal amounts of starch, DF, protein and energy, which was successfully accomplished (Table 2). The three diets used for intervention were characterised by a low content of cellulose $(12-17 \mathrm{~g} / \mathrm{kg} \mathrm{DM})$ and a high content of AX $(50-62 \mathrm{~g} / \mathrm{kg}$ $\mathrm{DM})$. The content of $\mathrm{AX}$ was $22-24 \%$ higher in WWG and WAF breads than in RAF bread, and the $\beta$-glucan content was double in WAF and RAF breads (8-9 g/kg DM) compared to WWG bread ( $\mathrm{g} / \mathrm{kg}$ DM). The dietary content of soluble DF was relatively high in RAF bread 
Table 3. Daily intake of feed, nutrients and energy on day 7 in the experimental week of pigs fed either whole-wheat grain (WWG), wheat aleurone-rich flour (WAF) or rye aleurone-rich flour (RAF) diets

\begin{tabular}{|c|c|c|c|c|c|}
\hline & \multicolumn{3}{|c|}{ Diet } & \multicolumn{2}{|c|}{$P$} \\
\hline & WWG & WAF & RAF & SEM & Diet \\
\hline \multicolumn{6}{|l|}{ Intake (g/d) } \\
\hline Feed & $2550^{a}$ & $2185^{\mathrm{b}}$ & $2161^{b}$ & 52 & $<0.001$ \\
\hline DM & $1669^{a}$ & $1537^{b}$ & $1494^{b}$ & 36 & 0.02 \\
\hline Starch & $844^{\mathrm{a}}$ & $722^{b}$ & $754^{\mathrm{b}}$ & 18 & 0.002 \\
\hline Dietary fibre* & 207 & 211 & 196 & 5 & $0 \cdot 11$ \\
\hline Gross energy (MJ/d) & $33.9^{a}$ & $31 \cdot 3^{b}$ & $30 \cdot 5^{\mathrm{b}}$ & 0.7 & 0.02 \\
\hline Digested energy $(\mathrm{MJ} / \mathrm{d}) \dagger$ & $28.0^{\mathrm{a}}$ & $24 \cdot 6^{\mathrm{b}}$ & $24 \cdot 0^{\mathrm{b}}$ & 0.6 & 0.002 \\
\hline
\end{tabular}

(29 $\mathrm{g} / \mathrm{kg} \mathrm{DM})$, intermediate in WWG bread $(23 \mathrm{~g} / \mathrm{kg} \mathrm{DM})$ and low in WAF bread $(13 \mathrm{~g} / \mathrm{kg} \mathrm{DM})$. The WFL bread used as a washout diet had a high content of cellulose $(66 \mathrm{~g} / \mathrm{kg} \mathrm{DM})$ originating from the Vitacel fibre and low contents of soluble fibre (14 g/ kg DM), AX (26 g/kg DM) and $\beta$-glucan $(1 \mathrm{~g} / \mathrm{kg} \mathrm{DM})$.

The pigs had a lower intake of feed $(P<0 \cdot 001)$ and DM $(P=0.02)$ when fed aleurone breads (WAF and RAF) as compared to WWG bread (Table 3). Consequently, the daily intake of starch was reduced by 14 and $11 \%$ in pigs fed WAF and RAF breads, whereas the intake of digestible energy was reduced by 12 and $14 \%$, respectively. The daily intake of DF amounted to $196-211 \mathrm{~g} / \mathrm{d}$ and was comparable among breads $(P>0 \cdot 10)$

\section{Effects on metabolites in arterial and portal blood}

In arterial blood, insulin was highest $(P<0 \cdot 01)$ whereas propionate was lowest $(P<0.05)$ when the pigs were fed WWG breads compared to when the pigs were fed WAF and RAF breads (Table 4), whereas all other plasma metabolites were not affected by the dietary intervention in arterial blood. The dietary effects on plasma insulin and propionate found in arterial blood were consistent

Table 4. Mean plasma concentrations of metabolites $(0-10 \mathrm{~h}$ after the first daily meal) in the mesenteric artery and the portal vein in pigs fed either whole-wheat grain (WWG), wheat aleurone-rich flour (WAF) or rye aleurone-rich flour (RAF) breads

\begin{tabular}{|c|c|c|c|c|c|c|c|}
\hline & \multicolumn{3}{|c|}{ Diet } & \multirow[b]{2}{*}{ SEM } & \multicolumn{3}{|c|}{$P$} \\
\hline & WWG & WAF & RAF & & Diet & Time & Diet $\times$ time \\
\hline \multicolumn{8}{|l|}{ Mesenteric artery } \\
\hline Insulin $(\mathrm{pmol} / /)^{*}$ & $73^{\mathrm{a}}(55,96)$ & $53^{b}(41,70)$ & $59^{\mathrm{a}, \mathrm{b}}(45,78)$ & - & 0.006 & $<0.001$ & 0.77 \\
\hline Glucose $(\mathrm{mmol} / \mathrm{l})$ & $6 \cdot 28$ & 6.03 & $6 \cdot 15$ & 0.14 & 0.21 & $<0.001$ & 0.76 \\
\hline Lactate $(\mathrm{mmol} / \mathrm{l})$ & 0.83 & 0.75 & 0.81 & 0.04 & 0.34 & $<0.001$ & 0.04 \\
\hline SCFA $(\mu \mathrm{mol} / \mathrm{l})$ & 276 & 271 & 258 & 19 & 0.75 & 0.05 & 0.20 \\
\hline Acetate $(\mu \mathrm{mol} / \mathrm{l})$ & 251 & 244 & 231 & 20 & $0 \cdot 70$ & 0.04 & 0.20 \\
\hline Propionate $(\mu \mathrm{mol} / \mathrm{l})$ & $6 \cdot 4^{\mathrm{b}}$ & $8 \cdot 2^{\mathrm{a}}$ & $8 \cdot 1^{\mathrm{a}}$ & 0.6 & 0.03 & 0.99 & 0.38 \\
\hline Butyrate $(\mu \mathrm{mol} / \mathrm{l})$ & 7.9 & $10 \cdot 2$ & $9 \cdot 3$ & $1 \cdot 3$ & 0.28 & 0.50 & 0.66 \\
\hline Valerate $(\mu \mathrm{mol} / /)$ & 0.4 & 0.5 & 0.7 & 0.1 & 0.13 & 0.01 & 0.06 \\
\hline Caproate $(\mu \mathrm{mol} / \mathrm{l})$ & $2 \cdot 2$ & $2 \cdot 4$ & 1.8 & 0.4 & 0.61 & 0.28 & 0.38 \\
\hline $\mathrm{BCFA}(\mu \mathrm{mol} / \mathrm{l})$ & $6 \cdot 5$ & $5 \cdot 9$ & $6 \cdot 1$ & 0.6 & 0.70 & 0.34 & 0.81 \\
\hline Iso-butyrate $(\mu \mathrm{mol} / \mathrm{l})$ & $2 \cdot 9$ & 2.9 & $3 \cdot 3$ & 0.3 & 0.48 & 0.007 & 0.35 \\
\hline Iso-valerate $(\mu \mathrm{mol} / \mathrm{l})$ & $3 \cdot 7$ & $3 \cdot 0$ & $2 \cdot 8$ & 0.4 & 0.13 & 0.49 & 0.50 \\
\hline \multicolumn{8}{|l|}{ Portal vein } \\
\hline Insulin $(\mathrm{pmol} / \mathrm{l})^{\star}$ & $129^{a}(90,183)$ & $87^{\mathrm{b}}(61,124)$ & $88^{b}(62,125)$ & - & 0.003 & $<0.001$ & 0.93 \\
\hline Glucose $(\mathrm{mmol} / \mathrm{l})$ & 8.86 & 8.01 & 8.51 & 0.24 & 0.08 & $<0.001$ & 0.22 \\
\hline Lactate $(\mathrm{mmol} / \mathrm{l})$ & 1.13 & 1.00 & 1.08 & 0.04 & 0.09 & $<0.001$ & 0.01 \\
\hline $\operatorname{SCFA}(\mu \mathrm{mol} / \mathrm{l})$ & 661 & 699 & 783 & 55 & 0.22 & 0.09 & 0.28 \\
\hline Acetate $(\mu \mathrm{mol} / \mathrm{l})$ & 483 & 474 & 536 & 37 & 0.42 & 0.04 & 0.32 \\
\hline Propionate $(\mu \mathrm{mol} / \mathrm{l})$ & $103^{\mathrm{b}}$ & $143^{a}$ & $153^{\mathrm{a}}$ & 15 & 0.04 & 0.25 & 0.33 \\
\hline Butyrate $(\mu \mathrm{mol} / \mathrm{l})$ & $42^{\mathrm{b}}$ & $51^{\mathrm{a}, \mathrm{b}}$ & $56^{\mathrm{a}}$ & 8 & 0.03 & 0.78 & 0.17 \\
\hline Valerate $(\mu \mathrm{mol} / \mathrm{l})$ & $8 \cdot 7^{\mathrm{b}}$ & $9 \cdot 3^{b}$ & $13^{\mathrm{a}}$ & $1 \cdot 2$ & 0.001 & 0.15 & 0.18 \\
\hline Caproate $(\mu \mathrm{mol} / \mathrm{l})$ & $4.0^{\mathrm{b}}$ & $3 \cdot 5^{\mathrm{b}}$ & $5 \cdot 6^{\mathrm{a}}$ & 0.5 & 0.03 & 0.15 & $0 \cdot 12$ \\
\hline $\mathrm{BCFA}(\mu \mathrm{mol} / \mathrm{l})$ & 20 & 18 & 20 & 1.6 & 0.47 & 0.03 & 0.57 \\
\hline Iso-butyrate $(\mu \mathrm{mol} / \mathrm{l})$ & 8.8 & 8.2 & 9.7 & 0.7 & 0.37 & 0.03 & 0.15 \\
\hline Iso-valerate $(\mu \mathrm{mol} / \mathrm{l})$ & 11.6 & $9 \cdot 6$ & $10 \cdot 7$ & 0.9 & 0.26 & 0.05 & 0.90 \\
\hline
\end{tabular}

* SEM is not an appropriate measure of variance because data were logarithmically transformed before data analysis. Instead, $95 \%$ confidence limits are given in brackets. 
Table 5. Portal blood flow (l/min), apparent insulin secretion (nmol/h) and portal NEFA content ( $\mu$ eqv) and absorption of nutrients (mmol/h) and energy (kJ/h) derived from assimilated carbohydrates at fast and during two postprandial phases (I, $0-2.5 \mathrm{~h}$, II, 2.5-5 h post feeding) in pigs fed either whole-wheat grain (WWG), wheat aleurone-rich flour (WAF) or rye aleurone-rich flour (RAF) breads at the first ( 09.00 hours) and second daily meals ( 14.00 hours) on day 7 of an experimental week

\begin{tabular}{|c|c|c|c|c|c|c|c|c|c|c|c|c|c|c|}
\hline \multirow[b]{2}{*}{ Main effects } & \multicolumn{3}{|c|}{ Diet } & \multirow[b]{2}{*}{ SEM } & \multirow[b]{2}{*}{ Fast $^{\star}$} & \multicolumn{2}{|c|}{ First meal } & \multicolumn{2}{|c|}{ Second meal } & \multirow[b]{2}{*}{ SEM } & \multicolumn{4}{|c|}{$P$} \\
\hline & WWG & WAF & RAF & & & $\mathrm{Ph} \mathrm{I}$ & $\mathrm{Ph}$ II & $\mathrm{Ph} \mathrm{I}$ & $\mathrm{Ph} I \mathrm{I}$ & & Diet & Meal & Phase & $\mathrm{M} \times \mathrm{P}$ \\
\hline Blood flow (1/min) & 1.45 & 1.54 & 1.47 & $0 \cdot 13$ & $1.01^{d}$ & $1.46^{b, c}$ & $1.41^{\mathrm{c}}$ & $1 \cdot 61^{\mathrm{a}}$ & $1.48^{\mathrm{b}}$ & $0 \cdot 10$ & 0.80 & $<0.001$ & $<0.001$ & 0.04 \\
\hline $\begin{array}{l}\text { Insulin secreted } \\
(\mathrm{nmol} / \mathrm{h})\end{array}$ & $5 \cdot 9^{\mathrm{a}}$ & $5 \cdot 4^{\mathrm{a}, \mathrm{b}}$ & $3.9^{\mathrm{b}}$ & $1 \cdot 2$ & $1 \cdot 3^{d}$ & $8 \cdot 8^{a}$ & $4 \cdot 4^{\mathrm{b}}$ & $4 \cdot 3^{b}$ & $2 \cdot 8^{\mathrm{C}}$ & $1 \cdot 1$ & 0.04 & $<0.001$ & $<0.001$ & $<0.005$ \\
\hline NEFA ( $\mu$ eqv)† & $\begin{array}{c}105 \\
(92,120)\end{array}$ & $\begin{array}{c}102 \\
(89,117)\end{array}$ & $\begin{array}{c}99 \\
(86,113)\end{array}$ & - & $172^{\mathrm{a}}$ & $\begin{array}{c}93^{\mathrm{c}} \\
(82,104)\end{array}$ & $\begin{array}{l}102^{\mathrm{C}} \\
(90,114)\end{array}$ & $\begin{array}{l}115^{\mathrm{b}} \\
(102,129)\end{array}$ & $\begin{array}{l}100^{c} \\
(89,113)\end{array}$ & - & 0.65 & 0.007 & 0.56 & 0.003 \\
\hline \multicolumn{15}{|c|}{ Portal absorption $(\mathrm{mmol} / \mathrm{h})$} \\
\hline Glucose & 227 & 217 & 218 & 20 & $-7.6^{\mathrm{c}}$ & $246^{\mathrm{a}}$ & $195^{\mathrm{b}}$ & $243^{\mathrm{a}}$ & $201^{\mathrm{b}}$ & 14 & 0.91 & 0.89 & $<0.001$ & 0.65 \\
\hline Lactate & 27 & 24 & 24 & $2 \cdot 0$ & $4 \cdot 2^{\mathrm{c}}$ & $28^{\mathrm{a}}$ & $22^{\mathrm{b}}$ & $28^{\mathrm{a}}$ & $23^{\mathrm{b}}$ & 1.6 & 0.47 & 0.89 & $<0.001$ & 0.65 \\
\hline SCFA & $33^{\mathrm{b}}$ & $39^{a, b}$ & $46^{a}$ & $4 \cdot 2$ & $39^{a, b}$ & $34^{\mathrm{b}}$ & $32^{\mathrm{b}}$ & $46^{\mathrm{a}}$ & $47^{\mathrm{a}}$ & 3.4 & 0.07 & $<0.001$ & 0.81 & 0.53 \\
\hline Acetate & 20 & 21 & 27 & $2 \cdot 7$ & $22^{a, b}$ & $19^{b}$ & $19^{\mathrm{b}}$ & $26^{a}$ & $27^{\mathrm{a}}$ & 1.9 & $0 \cdot 17$ & $<0.001$ & 0.98 & 0.80 \\
\hline Propionate & $8.2^{\mathrm{b}}$ & $12^{\mathrm{a}}$ & $13^{\mathrm{a}}$ & $1 \cdot 1$ & $11^{\mathrm{a}, \mathrm{b}}$ & $9.5^{\mathrm{b}}$ & $8 \cdot 6^{\mathrm{b}}$ & $13^{\mathrm{a}}$ & $13^{\mathrm{a}}$ & 0.9 & 0.01 & $<0.001$ & 0.76 & $0 \cdot 16$ \\
\hline Butyrate & $2 \cdot 9^{\mathrm{b}}$ & $3 \cdot 9^{a, b}$ & $4.1^{\mathrm{a}}$ & 0.6 & $4 \cdot 0^{\mathrm{a}, \mathrm{b}}$ & $3 \cdot 3^{\mathrm{b}}$ & $2 \cdot 9^{\mathrm{b}}$ & $4 \cdot 2^{\mathrm{a}}$ & $4 \cdot 2^{\mathrm{a}}$ & 0.6 & 0.02 & $<0.001$ & 0.19 & 0.29 \\
\hline Valerate & $0.70^{\mathrm{b}}$ & $0.84^{\mathrm{b}}$ & $1 \cdot 1^{\mathrm{a}}$ & 0.13 & $0 \cdot 81^{a, b}$ & $0.75^{\mathrm{b}}$ & $0.67^{\mathrm{b}}$ & $1 \cdot 0^{\mathrm{a}}$ & $1 \cdot 1^{\mathrm{a}}$ & 0.12 & 0.003 & $<0.001$ & 0.79 & 0.14 \\
\hline Caproate & $0.15^{\mathrm{b}}$ & $0.12^{\mathrm{b}}$ & $0.33^{\mathrm{a}}$ & 0.03 & $0.21^{\mathrm{b}}$ & $0.19^{b}$ & $0 \cdot 13^{\mathrm{c}}$ & $0.21^{b}$ & $0 \cdot 28^{a}$ & 0.03 & 0.001 & 0.008 & 0.80 & $<0.001$ \\
\hline \multicolumn{15}{|c|}{ Portal absorption of energy $(\mathrm{kJ} / \mathrm{h})$ derived from } \\
\hline Glucose & 638 & 610 & 610 & 57 & $-21^{\mathrm{c}}$ & $689^{\mathrm{a}}$ & $545^{\mathrm{b}}$ & $681^{a}$ & $563^{b}$ & 39 & 0.91 & 0.89 & $<0.001$ & 0.65 \\
\hline Lactate & 37 & 33 & 33 & 3 & $6^{\mathrm{c}}$ & $39^{\mathrm{a}}$ & $30^{\mathrm{b}}$ & $38^{\mathrm{a}}$ & $31^{\mathrm{b}}$ & 2 & 0.47 & 0.89 & $<0.001$ & 0.65 \\
\hline SCFA & $43^{\mathrm{b}}$ & $51^{\mathrm{a}, \mathrm{b}}$ & $60^{\mathrm{a}}$ & 5 & $51^{\mathrm{a}, \mathrm{b}}$ & $45^{\mathrm{b}}$ & $41^{\mathrm{b}}$ & $59^{\mathrm{a}}$ & $60^{\mathrm{a}}$ & 5 & 0.03 & $<0.001$ & 0.66 & 0.37 \\
\hline $\begin{array}{l}\text { Total absorbed } \\
\text { energy }\end{array}$ & 718 & 693 & 704 & 60 & $35^{\mathrm{c}}$ & $772^{a}$ & $617^{\mathrm{b}}$ & $776^{a}$ & $654^{\mathrm{b}}$ & 41 & 0.95 & 0.56 & $<0.001$ & 0.57 \\
\hline
\end{tabular}

* Fasting levels were not included in the statistical meal $\times$ phase test. Significant differences between fasting and postprandial levels were obtained using Wald's test.

† SEM is not an appropriate measure of variance because data were logarithmically transformed before data analysis. Instead, $95 \%$ confidence limits are given in brackets. 
also in portal blood. Portal glucose concentration tended to be higher $(P=0.08)$ when the pigs were fed WWG breads, intermediate when fed RAF bread and lowest when fed WAF bread. In addition, portal butyrate was highest $(P<0.05)$ when the pigs were fed RAF bread, intermediate when fed WAF bread and lowest when fed WWG bread. Furthermore, portal concentrations of valerate $(P<0.001)$ and caproate $(P<0.05)$ were higher when the pigs were fed RAF bread compared to WAF and WWG breads. Concentrations of plasma insulin, glucose, lactate $(P<0 \cdot 001)$, total SCFA $(P<0 \cdot 10)$, acetate and iso-butyrate $(P<0.05)$ were affected by the time after feeding, both in arterial and in portal blood. In addition, the concentration of plasma valerate in arterial blood and concentrations of BCFA and iso-valerate in portal blood were affected by the time after feeding.

Dietary effects on portal blood flow, insulin secretion, plasma NEFA and portal absorption of nutrients and energy

Portal blood flow was not affected by the three experimental diets $(P>0 \cdot 10$; Table 5$)$. The apparent insulin secretion was $51 \%$ higher $(P=0.04)$ in pigs fed WWG bread as compared to RAF bread, whereas insulin secretion was intermediate in pigs fed WAF bread. No dietary effects were observed on portal NEFA concentration $(P>0 \cdot 10)$. Furthermore, the net absorption of glucose and lactate $(P>0 \cdot 10)$ was comparable among the three diets and amounted to $217-227 \mathrm{mmol} / \mathrm{h}$ of glucose and $24-27 \mathrm{mmol} / \mathrm{h}$ of lactate, respectively. Absorption of acetate was not affected by diet $(P>0 \cdot 10)$, whereas absorption of propionate was $46-58 \%$ higher $(P<0.05)$ in pigs fed WAF and RAF breads compared to pigs fed WWG bread. Absorption of butyrate in pigs fed WAF and RAF breads increased by $34-41 \%$ compared to pigs fed WWG bread. Absorption of valerate was $42 \%$ higher $(P<0.01)$ and absorption of caproate was $244 \%$ higher after RAF bread consumption $(P<0 \cdot 01)$ as compared to consumption of WAF and WWG breads. Thus, in summary, the absorption of energy deriving from glucose and lactate was not influenced by the breads, whereas absorbed energy derived from SCFA $(P<0.05)$ was highest, intermediate and lowest in pigs fed RAF, WAF and WWG breads, respectively.

Effects of meals and postprandial phases on portal blood flow, insulin secretion, plasma NEFA and portal absorption of nutrients and energy

Apparent insulin secretion after the first daily meal was twofold higher than after the second daily meal ( $8.8 v$. $4.4 \mathrm{nmol} / \mathrm{h}, P<0.001$; Table 5), and in the first $2.5 \mathrm{~h}$ of the postprandial period, it was 1.5 times higher than in the following $2.5 \mathrm{~h}$ period $(4.3$ v. $2.8 \mathrm{nmol} / \mathrm{h}, P<0.001)$. Plasma NEFA concentration was reduced postprandially compared to concentration at fasting, but the NEFA concentration was higher $(P<0.05)$ in the first $2.5 \mathrm{~h}$ period after the second daily meal than the first daily meal. Portal absorption of glucose and lactate was $21-28 \%$ higher during the first $2.5 \mathrm{~h}$ of the postprandial period when compared to the consecutive $2.5 \mathrm{~h}$ period, whereas no meal effects were observed on absorption of glucose and lactate. In contrast, absorption of SCFA was comparable between the postprandial periods and differed between meals. Indeed, absorption of total and all individual SCFA was 35-53\% higher after consumption of the second daily meal than the first daily meal. Net portal absorption of energy changed with time after feeding and depended on the specific nutrient (Table 5). Glucose and lactate were predominantly absorbed during the first $2.5 \mathrm{~h}$ after feeding, and this pattern was consistent after both meals. In contrast, energy supplied to the portal vein as SCFA did not vary from the first $2.5 \mathrm{~h}$ to the next $2.5 \mathrm{~h}$ absorptive period within a meal, but the energy absorbed as SCFA was higher after the second daily meal than after the first daily meal. In total, the net portal absorption of energy originating from glucose, lactate and SCFA differed from the first to the second $2.5 \mathrm{~h}$ postprandial interval, whereas net portal absorption of energy in the $5 \mathrm{~h}$ following breakfast and lunch meals was comparable.

\section{Postprandial dynamics of insulin secretion and absorption of glucose and lactate}

Apparent insulin secretion (Fig. 1(a)) increased immediately after feeding, peaked $15-45 \mathrm{~min}$ after feeding and decreased thereafter. The apparent insulin secretion was inversely correlated to the net portal absorption of acetate $(r-0.24, P=0.04)$, propionate $(r-0.39, P=0.001)$ and butyrate $(r-0.35, P=0.003)$, but was not correlated with net portal absorption of glucose $(r 0 \cdot 15, P>0 \cdot 10)$. Like insulin secretion, the net portal absorption of glucose (Fig. 1(b)) and lactate (Fig. 1(c)) increased immediately after feeding. Glucose peaked after 45-60 min, whereas lactate peaked $60 \mathrm{~min}$ after feeding. The log of net portal glucose absorption plotted against time after feeding was linear in the interval $1-5 \mathrm{~h}$ as predicted by a first-order kinetic pool model, and slopes were $-4 \cdot 5,-4.8$ and $-8.0 \% / \mathrm{h}$ for WWG, WAF and RAF breads, respectively (Fig. 2). The slope tended to be steeper $(P=0.07)$ for the RAF bread as compared to the two wheat breads. The log of net portal lactate absorption plotted against time after feeding was also linear in the interval $1-5 \mathrm{~h}$ after feeding with a slope of -5.9 ( affected by diets $(P>0 \cdot 10)$.

\section{Discussion}

Dietary effects on glycaemic response

The net glucose absorption in the present study (217- $227 \mathrm{mmol} / \mathrm{h})$ was comparable during the postprandial period with that observed in other studies with 

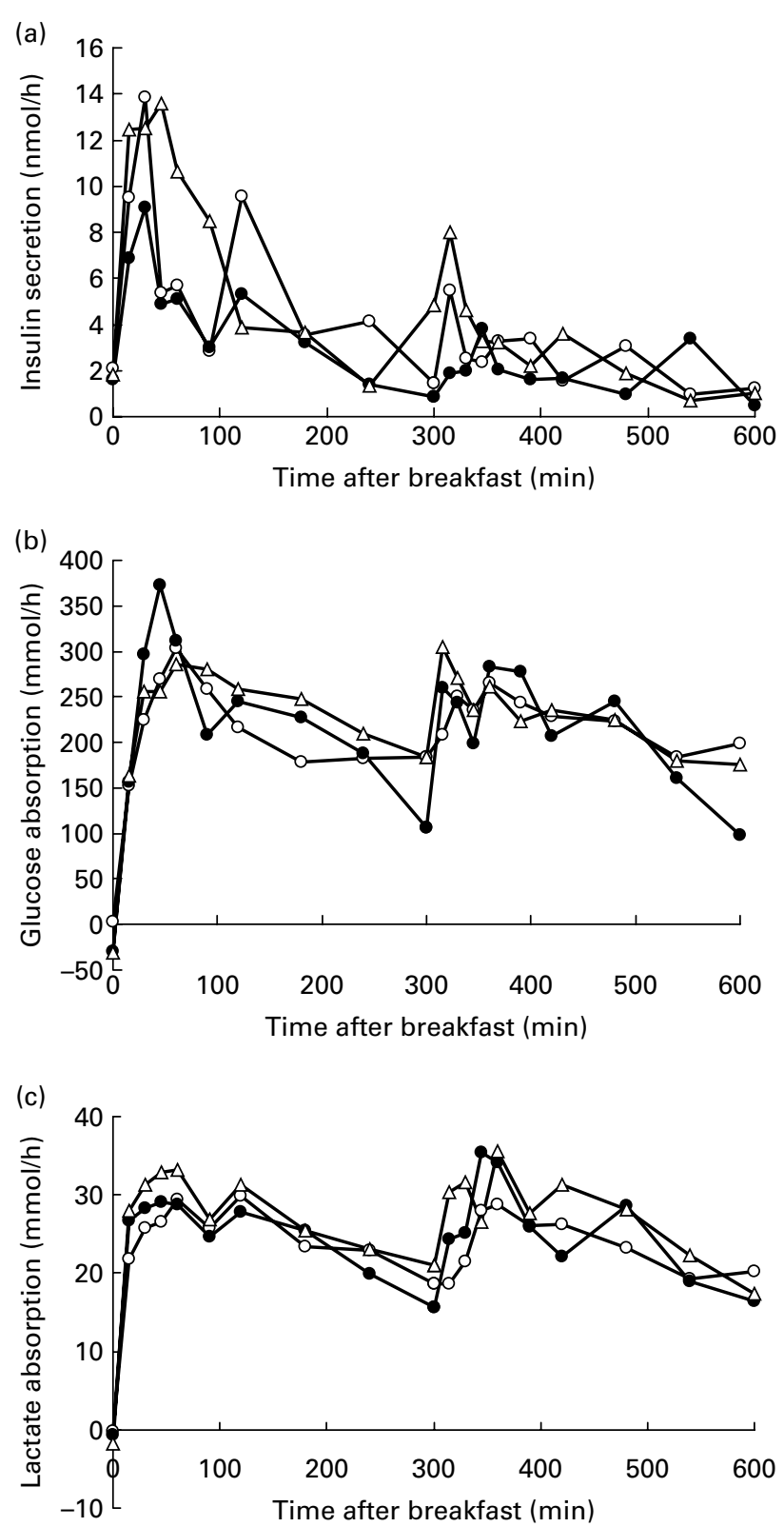

Fig. 1. (a) Apparent insulin secretion (nmol/h): diet $P=0.04$, time $(\mathrm{T})$ $P<0.001$, meal (M) $P<0.001, M \times T P=0.49$, (b) glucose absorption (mmol/h): diet $P=0.84$, time (T) $P<0.12$, meal (M) $P<0.001, M \times T$ $P<0.001$ and (c) lactate absorption $(\mathrm{mmol} / \mathrm{h})$ : diet $P=0.39$, time (T) $P<0.001$, meal (M) $P=0.09, M \times T P<0.001$ in pigs fed whole-wheat grain $(-\triangle-)$, wheat aleurone-rich flour $\left(-O_{-}\right)$or rye aleurone-rich flour $\left(-\bullet_{-}\right)$ breads during the first $10 \mathrm{~h}$ after receiving the first daily meal (the second daily meal was given $5 \mathrm{~h}$ later, i.e. at time $=300 \mathrm{~min}$ ).

growing pigs ${ }^{(14,35,36)}$. However, the net glucose absorption in the present study was higher than that of observed when pigs were fed resistant $\operatorname{starch}^{(36,37)}$. The reason is most likely that cereal starch has an open structure which enables easy access for $\alpha$-amylase to degrade $\operatorname{starch}^{(38)}$. In a parallel study with twenty ileum-fistulated pigs, we found an increased luminal viscosity and a lowered digestibility of starch in the small intestine when feeding RAF bread $^{(21,22)}$, but the higher luminal viscosity and lower starch digestibility did not reduce glucose absorption in the present study. However, pigs consuming RAF bread in the present study seemed to respond differently compared to pigs fed WWG and WAF breads regarding the pattern of net portal glucose absorption. Indeed, the log of net portal flux of glucose indicated that starch was digested and glucose was absorbed faster when pigs were fed RAF breads. A likely explanation for this is that RAF bread contained no natural gluten ${ }^{(39)}$.

\section{Dietary effects on insulinaemic response}

Consumption of RAF bread lowered the insulinaemic response compared to WWG bread, while WAF bread was intermediate. Several studies indicate that the presence of intact kernels is better than starch in attenuating the insulinaemic response ${ }^{(11,40)}$, whereas the amount of DF is of less importance for the insulinaemic response. However, in the present study, the breads prepared from RAF and WAF did indeed attenuate the insulinaemic response to a greater extent than did WWG. It is logical to suggest that it was either the rye per se or bioactive components from the aleurone layer that were responsible for the attenuated insulinaemic response. In a recent study, rye breads based on endosperm or whole grain have been shown to lower insulinaemic responses and improve glycaemic profiles ${ }^{(41)}$, which supports the notion that rye possesses healthpromoting properties. Indeed, Rosen et al. ${ }^{(41)}$ speculated that unknown bioactive components could be responsible for these beneficial features of rye. The other possible mechanism is that the aleurone fractions of both wheat and rye contain bioactive components that are able to improve insulin economy. No matter whether it is an unknown 'rye factor' or bioactive components in the aleurone fraction, the lowered insulinaemic response was not associated with an insufficient insulin signal. Indeed, numerically lower levels of plasma NEFA and higher glucose concentrations in the artery and the portal vein $(P=0.08)$ were observed along with the lower insulin secretion, and these findings suggest that the peripheral insulin sensitivity was improved in pigs fed RAF breads. A likely explanation for these results is that the affinity of

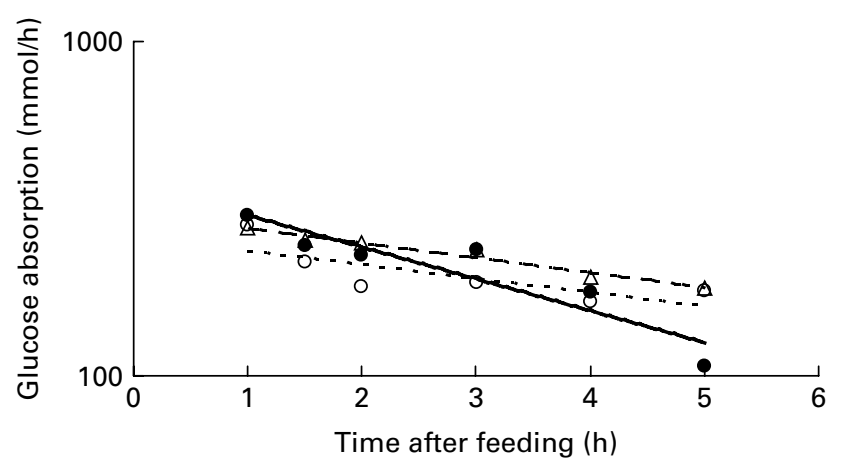

Fig. 2. Net portal absorption (log scale) of glucose in pigs fed whole-wheat grain $(--\triangle--)$, wheat aleurone-rich flour (--O--) or rye aleurone-rich flour breads (-๑). 
the insulin receptors in muscle and fat tissues was improved by aleurone breads, which enhanced the overall insulin economy. In support of this, Fukagawa et al. ${ }^{(42)}$ demonstrated that DF originating from whole grains and vegetables was able to improve the peripheral sensitivity to insulin in young and elderly human subjects. It should be emphasised, however, that the lower feed intake observed when pigs were fed rye or wheat aleurone may have contributed to a minor extent in lowering the insulin response.

\section{Butyrate - a possible candidate in regulating insulin secretion}

Past studies have primarily focused on butyrate as an important nutrient for health and maintenance of the epithelium of the large intestine. More recently, studies have pointed to butyrate as an important nutrient in the release of hormones regulating energy homoeostasis ${ }^{(43)}$, for $\left\ulcorner\right.$ improved insulin sensitivity ${ }^{(18)}$ and for increased energy expenditure in animals. Zhou et al. ${ }^{(43)}$ reported that butyrate stimulated expression of peptide YY and proglucagon genes in caecum and colon cells in rats, thereby signalling satiety. Gao et $a l{ }^{(18)}$ found that butyrate increased the energy expenditure, increased the mitochondrial function in brown adipose tissue and improved the insulin sensitivity of obese rats. In the present study, the highest total absorption of SCFA and absorption of butyrate after consumption of RAF bread were associated with the lowest insulin secretion. Although the production of butyrate in cereal diets is linked to the digestion of AX in the gut ${ }^{(44)}$, the higher production of butyrate with RAF diets can probably be associated with the high dietary contents of fructans, $\beta$-glucans and lower starch digestibility ${ }^{(21)}$. A higher butyrate production may indeed be a central player for the insulinaemic response. In support of that, an increase in butyrate absorption at the second (compared to first) daily meal was also associated with a lower insulin secretion. In addition, animals whose colon has been removed surgically face problems in regulating the plasma level of glucose, as reviewed by Robertson ${ }^{(12)}$, which also suggests that butyrate may be an important metabolite for regulating insulin response. Indeed, an increasing body of evidence indicates that butyrate has multiple and adverse biological effects, and this aspect certainly deserves further attention.

\section{First v. second daily meal}

In the present study, a higher apparent insulin secretion was observed during the postprandial period after the first daily meal than after the second daily meal $(P<0 \cdot 001)$. The attenuated insulin secretion following the second daily meal could not be attributed to an altered need to regulate blood glucose level because the meals supplied equal amounts of starch, and the total absorption of glucose was comparable in the postprandial periods following the first and second daily meals. Instead, the present results indicate that insulin secretion and thus insulin economy may vary considerably diurnally, and the applied feeding strategy may be a major contributor. The pigs in the present study were fed $40 \%$ of the daily allowance at the first and second daily meals but $20 \%$ at the third daily meal, and meals were provided with $5 \mathrm{~h}$ between servings. Thus, the pigs were in a catabolic state before the first daily meal, as indicated by a negative net portal flux of glucose (indicating mobilisation of glycogen or gluconeogenesis) and high NEFA levels (indicating mobilisation of fat). In contrast, the pigs were in an anabolic state when offered the second daily meal. In a previous study where pigs were fed three meals a day of equal size approximately every eighth hour, no profound insulin secretion was observed following consumption of the first daily meal $^{(45)}$. But when pigs were fasted for $24 \mathrm{~h}$ and then fed a single meal, they responded by eliciting a profoundly higher insulin secretion, which was also associated with a low glucose clearance from the blood during the postprandial period $^{(45)}$. Taken together, these results suggest that the insulin secretion, insulin sensitivity and thereby insulin economy are affected by the diurnal variation in energy supplied from the gastrointestinal tract. Hence, both a high-GI diet and large diurnal fluctuations in energy balance seem to be associated with higher insulin secretion. It should be underlined, though, that with the present pig model, it was not possible to investigate how the liver responded to altered portal energy supply following postprandial periods after breakfast and lunch meals.

In conclusion, insulin secretion was lowered in pigs fed RAF breads (compared to WWG bread) in spite of a similar intake of starch. Rye caused a higher luminal viscosity, which is expected to lower or slow the glucose absorption profile, which was not observed in the present study. The low insulin secretion following consumption of rye (and to a lesser extent following consumption of wheat aleurone) was associated with a high absorption of butyrate originating from bacterial fermentation in the caecum and colon, and an increasing body of evidence suggests a direct link between dietary stimulation of butyrate production and insulin economy.

\section{Acknowledgements}

The authors thank Helle Handll Christensen, Winnie Østergaard Thomsen, Kathrine Høirup Hansen and Lisbeth Märcher for technical assistance. The present research was financially supported by the European Commission in the Communities Sixth Framework Programme, Project HEALTHGRAIN (FOOD-CT-2005-514008). It reflects the authors' views, and the community is not liable for any use that may be made of the information contained in this publication. K. E. B. K. and A. S. were responsible for project development. P. K. T., J. H. and H. J. conducted the nutritional experiments in pigs. P. K. T. was responsible 
for the analyses and for generating statistical analyses. P. K. T. and K. E. B. K. were responsible for drafting the manuscript and P. K. T. is the corresponding author. There are no conflicts of interest.

\section{References}

1. Fagt S, Matthiessen J, Biltoft-Jensen A, et al. (2004) Udviklingen $i$ danskernes kost 1985-2001 med fokus på sukker alkohol samt motivation og barrierer for sund livsstil (Developments in The Danish Diet 1985-2001 with a Focus on Sugar Alcohol, Motivation and Barriers to Healthy Lifestyle), pp. 127. Copenhagen: Danish Institute for Food and Veterinary Research.

2. Sørensen A-M, Fagt S \& Møller A (1993) Dietary fibre intake in Denmark. In Dietary Fibre Intakes in Europe, pp. 37-39 [JH Cummings and W Frølich, editors]. Brussels: DirectorateGeneral Science, Research and Development.

3. Slavin J (2004) Whole grains and human health. Nutr Res Rev 17, 99-110.

4. Jacobs DR Jr, Andersen LF \& Blomhoff R (2007) Wholegrain consumption is associated with a reduced risk of noncardiovascular, noncancer death attributed to inflammatory diseases in the Iowa Women's Health Study. Am J Clin Nutr 85, 1606-1614.

5. Salmerón J, Manson JE, Stampfer MJ, et al. (1997) Dietary fiber, glycemic load, and risk of non-insulin-dependent diabetes mellitus in women. JAMA 277, 472-477.

6. Livesey G, Taylor R, Hulshof T, et al. (2008) Glycemic response and health - a systematic review and metaanalysis: relations between dietary glycemic properties and health outcomes. Am J Clin Nutr 87, 258S-268S.

7. Livesey G, Taylor R, Hulshof T, et al. (2008) Glycemic response and health - a systematic review and metaanalysis: the database, study characteristics, and macronutrient intakes. Am J Clin Nutr 87, 223S-236S.

8. Wood PJ (2007) Cereal $\beta$-glucans in diet and health. J Cereal Sci 46, 230-238.

9. Lu ZX, Walker KZ, Muir JG, et al. (2000) Arabinoxylan fiber, a byproduct of wheat flour processing, reduces the postprandial glucose response in normoglycemic subjects. Am J Clin Nutr 71, 1123-1128.

10. Wood PJ, Beer MU \& Butler G (2000) Evaluation of role of concentration and molecular weight of oat beta-glucan in determining effect of viscosity on plasma glucose and insulin following an oral glucose load. Br J Nutr 84, 19-23.

11. Juntunen KS, Laaksonen DE, Autio K, et al. (2003) Structural differences between rye and wheat breads but not total fiber content may explain the lower postprandial insulin response to rye bread. Am J Clin Nutr 78, 957-964.

12. Robertson MD (2007) Metabolic cross talk between the colon and the periphery: implications for insulin sensitivity. Proc Nutr Soc 66, 351-361.

13. Priebe MG, Wang H, Weening D, et al. (2010) Factors related to colonic fermentation of nondigestible carbohydrates of a previous evening meal increase tissue glucose uptake and moderate glucose-associated inflammation. Am J Clin Nutr 91, 90-97.

14. Bach Knudsen KE (2005) Effect of dietary non-digestible carbohydrates on the rate of SCFA delivery to peripheral tissues. Food Ingred JJpn 210, 1008-1017.

15. Bach Knudsen KE, Serena A, Canibe N, et al. (2003) New insight into butyrate metabolism. Proc Nutr Soc 62, 81-86.

16. Robertson MD, Currie JM, Morgan LM, et al. (2003) Prior short-term consumption of resistant starch enhances postprandial insulin sensitivity in healthy subjects. Diabetologia 46, 659-665.

17. Robertson MD, Bickerton AS, Dennis AL, et al. (2005) Insulin-sensitizing effects of dietary resistant starch and effects on skeletal muscle and adipose tissue metabolism. Am J Clin Nutr 82, 559-567.

18. Gao Z, Yin J, Zhang J, et al. (2009) Butyrate improves insulin sensitivity and increases energy expenditure in mice. Diabetes 58, 1509-1517.

19. Jenkins DJ, Wolever TM, Taylor RH, et al. (1982) Slow release dietary carbohydrate improves second meal tolerance. Am J Clin Nutr 35, 1339-1346.

20. Nilsson A, Ostman E, Preston T, et al. (2008) Effects of GI vs content of cereal fibre of the evening meal on glucose tolerance at a subsequent standardized breakfast. Eur J Clin Nutr 62, 712-720.

21. LeGall M, Serena A, Jørgensen H, et al. (2009) The role of whole-wheat grain and wheat and rye ingredients on the digestion and fermentation processes in the gut - a model experiment with pigs. Br J Nutr 102, 1590-1600.

22. LeGall M, Eybye KL \& Bach Knudsen KE (2010) Molecular weight changes of arabinoxylans of wheat and rye incurred by the digestion processes in the upper gastrointestinal tract of pigs. Liv Sci (Epublication ahead of print version 9 September 2010).

23. Jørgensen H, Theil PK \& Engberg RM (2010) Surgical techniques for quantitative nutrient digestion and absorption studies in the pig. Liv Sci (In the Press).

24. AOAC (1990) Official Methods of Analysis, 15th ed. Arlington, VA: AOAC.

25. Hansen B (1989) Determination of nitrogen as elementary N, an alternative to Kjeldahl. Acta Agric Scand 39, 113-118.

26. Bligh EG \& Dyer WJ (1959) A rapid method of total lipid extraction and purification. Can J Biochem Physiol 37, 911-917.

27. Larsson K \& Bengtsson S (1983) Bestämning av lättilgängeliga kolbydrater $i$ växtmaterial (Determination of Readily Available Carbohydrates in Plant Material). National Laboratory of Agricultural Chemistry Methods Report no. 22. Uppasala: National Laboratory of Agricultural Chemistry.

28. Bach Knudsen KE (1997) Carbohydrate and lignin contents of plant materials used in animal feeding. Anim Feed Sci Technol 67, 319-338.

29. Theander O \& Åman P (1979) Studies on dietary-fibers .1. Analysis and chemical characterization of water-soluble and water-insoluble dietary-fibers. Swed J Agric Res 9, 97-106.

30. Brighenti F (1998) Summary of the conclusion of the working group on Profibreinterlaboratory study on determination of short chain fatty acids in blood. In Functional Properties of Non-digestible Carbohydrates, pp. 150-153 [F Gullion, R Amadò, MT Amaral-Collaco, H Andersson, NG Asp, KE Bach Knudsen, M Champ, J Mathers, JA Robertson, I Rowland and J Van Loo, editors]. Brussels: European Commission, DG XII, Science, Research and Development.

31. Løvendahl P \& Purup HM (2002) Technical note: timeresolved fluoro-immunometric assay for intact insulin in livestock species. J Anim Sci 80, 191-195.

32. Rérat AA, Vaissade P \& Vaugelade P (1984) Absorption kinetics of some carbohydrates in conscious pigs. 2. Quantitative aspects. BrJ Nutr 51, 517-529.

33. Weast RC, Astle MJ \& Beyer WH (1984) CRC Handbook of Chemistry and Physics. Boca Raton, FL: CRC Press, Inc.

34. Littell RC, Milliken GA, Stroup WW, et al. (1996) SAS (R) System for Mixed Models. Cary, NC: SAS Institute, Inc.

35. Bach Knudsen KE, Jørgensen, H \& Canibe N (2000) Quantification of the absorption of nutrients derived from 
carbohydrate assimilation: model experiment with catheterised pigs fed on wheat- or oat-based rolls. Br J Nutr 84, 449-458.

36. van der Meulen J, Bakker JGM, Smits B, et al. (1997) Effect of source of starch on net portal flux of glucose, lactate, volatile fatty acids and amino acids in the pig. BrJ Nutr 78, 533-544.

37. van der Meulen J, Bakker GCM, Bakker JGM, et al. (1997) Effect of resistant starch on net portal-drained viscera flux of glucose, volatile fatty acids, urea, and ammonia in growing pigs. I Anim Sci 75, 2697-2704.

38. Englyst HE, Kingman SM \& Cummings JH (1992) Classification and measurement of nutritionally important starch fractions. Eur J Clin Nutr 46, Suppl. 2, S33-S50.

39. Würsch P (1989) Starch in human nutrition. In Nutritional Value of Cereal Products, Beans and Starches, pp. 199-256, World Rev Nutr Diet 60 [GH Bourne, editor]. Basel: Karger.

40. Juntunen KS, Niskanen LK, Liukkonen KH, et al. (2002) Postprandial glucose, insulin, and incretin responses to grain products in healthy subjects. Am J Clin Nutr 75, 254-262.
41. Rosen LA, Silva LOB, Andersson UK, et al. (2009) Endosperm and whole grain rye breads are characterized by low postprandial insulin response and a beneficial blood glucose profile. Nutr J 8, 42.

42. Fukagawa NK, Anderson JW, Hageman G, et al. (1990) Highcarbohydrate, high-fiber diets increase peripheral insulin sensitivity in healthy young and old adults. Am J Clin Nutr 52, 524-528.

43. Zhou J, Hegsted M, McCutcheon KL, et al. (2006) Peptide YY and proglucagon mRNA expression patterns and regulation in the gut. Obesity (Silver Spring) 14, 683-689.

44. Bach Knudsen KE \& Lærke HN (2010) Rye arabinoxylans: molecular structure, physicochemical properties and physiological effects in the gastrointestinal tract. Cereal Chem $\mathbf{8 7}$, 353-362.

45. Bach Knudsen KE, Serena A, Kjaer AKB, et al. (2005) Rye bread enhances the production and plasma concentration of butyrate but not the plasma concentrations of glucose and insulin in pigs. J Nutr 135, 1696-1704. 